\title{
Design and simulation of Lidar based control system for wind turbine
}

\author{
Atif Iqbal ${ }^{1}$, Deng Ying ${ }^{2}$, Faheem Akhter ${ }^{3}$, Manoj Kumar Panjwani ${ }^{4}$, Danish Khan ${ }^{5}$ \\ 1,2,4,5 School of Renewable Energy \& Clean Energy, North China Electric Power University, Beijing, China \\ ${ }^{3,4}$ Department of Electrical Engineering, Sukkur IBA University, Sukkur, Pakistan
}

\begin{tabular}{|c|c|}
\hline Article Info & ABSTRACT \\
\hline Article history: & \multirow{9}{*}{$\begin{array}{l}\text { Renewable energy sources could be the main contributor to fulfilling the } \\
\text { world's energy requirement. Wind energy is grabbing the world's attention } \\
\text { due to its abundant nature and reliability. Wind energy is a prominent } \\
\text { renewable energy source due to its availability and higher reliability. Despite } \\
\text { the aforementioned benefits, there are some challenges such as wind } \\
\text { measurement and prediction due to the turbulent nature of the wind. Lidar } \\
\text { (light detection and ranging) technology is used in wind turbines to preview } \\
\text { the wind and act it accordingly. Wind speed along with the direction is } \\
\text { measured by the Lidar before it reaches the wind turbine plane and the } \\
\text { control system of the wind turbine utilizes this data for optimal results. It } \\
\text { enhances the control system along with it optimizes the output power. This } \\
\text { paper presents the Lidar simulation model, which previews the wind earlier } \\
\text { than the conventional feedback method. The Lidar simulation model is } \\
\text { prepared and implemented on the horizontal axis wind turbine. The } \\
\text { simulation is performed in GH Bladed at a } 2.0 \mathrm{MW} \text { wind turbine. The output } \\
\text { results are analyzed with the former method. The power extracted, pitch } \\
\text { angle, rotor torque obtained from the proposed methodology proves its } \\
\text { efficacy. }\end{array}$} \\
\hline Received Dec 16, 2020 & \\
\hline Revised Jan 2, 2021 & \\
\hline Accepted Feb 2, 2021 & \\
\hline Keywords: & \\
\hline Control system & \\
\hline Lidar & \\
\hline Power output & \\
\hline Wind turbines & \\
\hline
\end{tabular}

This is an open access article under the CC BY-SA license.

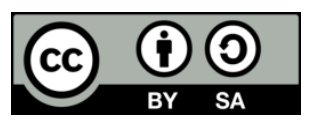

Corresponding Author:

Atif Iqbal

School of Renewable Energy \& Clean Energy

North China Electric Power University

Changping District, Beijing 102206, China

Email: atifiqbal@ncepu.edu.cn

\section{INTRODUCTION}

The world is getting polluted very quickly along with it the temperature is also increasing with the usage of traditional energy sources such as coal, oil and gas. The world is looking for alternate energy sources to counter these problems. Renewable energy sources are cleaner and greener among others[1], [2]. Various countries are supporting the use of renewable energy to meet their energy demand. Wind energy is a prominent renewable energy source due to its availability and higher reliability. Despite the aforementioned benefits, there are some challenges such as wind measurement and prediction due to the turbulent nature of the wind. Control techniques are developed to cater to these challenges. Conventional techniques have been applied by using the feedback controllers such as research was carried out by implementing the fuzzy logicbased PID controller to acquire the efficient output power [3], [4]. Fuzzy and adaptive fuzzy is implemented to achieve the utmost power output [5]-[7]. The improved PID controller was designed and implemented to enhance the output power as well as reduces the loading effect [8]. Another fuzzy controller is modeled to cater to the fatigue load by implementing the individual pitch control [9]. PI and PID controllers are 
implemented to acquire the maximum power output [10], [11]. Output power is enhanced by using the rotor speed as feedback [12]. The particle swarm optimization technique along with the fminsearch is used to tune the PID controller to operate the wind turbine efficiently and effectively [13]. All these techniques used are feedback, which works only with a change in response to the system which occurred already. Wind nature is very turbulent and unpredictable, the need is to design the feedforward control system which can preview the wind speed and adjust the control system accordingly. Various researches are performed in this field. A predictive controller is designed with the help of a fuzzy system to provide a reduced loading effect by adjusting the rotor speed [14]. The two predictive controllers are designed and implemented to act as Lidar sensors which compute and sense wind field [15]. Review papers have been written and various Lidar sensing techniques are discussed along with their benefits and challenges [16]-[18]. This research presents the yaw misalignments and how it can increase the loading effect, the correction of the yaw angle can reduce the loading effect significantly [19]. An adaptive control system is implemented to address the yaw alignment and wake effect furthermore, Yaw angle correction reduces the turbulence of downwind wind turbines [20]. Lidar technology is used to adjust the yaw angle as well as mitigate the wake effect by tracking the wake center [21]. The study of wake effect has been discussed and the main observation was the position of wind turbine nacelle also effects under specific wind directions [22]. This research proposes the feedforward control system based on Lidar technology to preview the wind field and measures it before it is touching the wind turbine plane. This can optimize the output power along with the safe and better operation of the wind turbine system.

Conventionally, the wind is measured through an anemometer in a wind turbine. The anemometer is placed along with the nacelle of the wind turbine. So, the wind is measured after it crosses the wind turbine rotor plane. The control system normally used feedback control acts accordingly, after wind surpasses the wind turbine. This makes the control system more challenging due to the turbulent nature of the wind. To cater to this problem Lidar is used in wind turbines which measures the wind before it crosses the rotor plane. Lidar uses the light sensor to measure the distance and speed of the wind. With the use of Lidar, wind turbulence and speed can be measured accurately and precisely. Lidar calculates the wind speed before time and the control system adjusts the blades to increase the power output and also protect the equipment [23]. There are two methods by which Lidar measures the data. Coherent and non-coherent detection. Coherent detection is normally used for doppler or phase-sensitive measurements through optical heterodyne measurement [24]. They require low power for operations but have complicated transceiver requirements. The two pulse models are used in the Lidar system; micro pulse and high energy system. The high energy system is used in measuring the atmospheric related data such as cloud data, strata, temperature, pressure, wind speed, humidity, cloud particles features [25], [26]. Various techniques are used to determine the wind speed direction and intensity which is very important to get the maximum yield. Weibull distribution is widely used over the last years for this purpose. The Weibull distribution's density function is provided in (1).

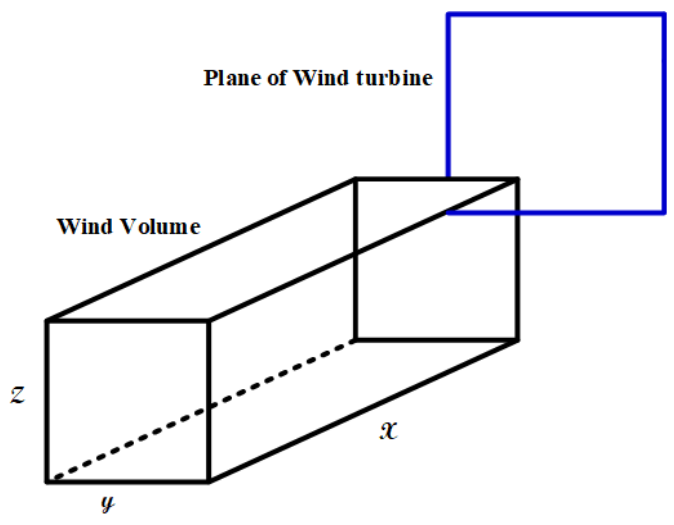

Figure 1. Wind structure used by Lidar passing through wind turbine

$$
f(v)=\frac{k}{c}\left(\frac{v}{c}\right)^{K-1} e^{-\left(\frac{v}{c}\right) K}
$$

Here, $f(v)$ represents the probability density factor, $v$ is the wind speed measured in $(\mathrm{m} / \mathrm{s})$, the scale factor is indicated by $\mathrm{c}$ while $\mathrm{k}$ denotes sharp factor [27]. 


$$
\begin{aligned}
& K=\left(\frac{\sum_{i=1}^{N} v_{i}^{K} \ln \left(v_{i}\right)}{\sum_{i=1}^{N} v_{i}^{K}}-\frac{\sum_{i=1}^{N} \ln \left(v_{i}\right)}{N}\right)^{-1} \\
& C=\left(\frac{1}{N} \sum_{i=1}^{N} v_{i}^{K}\right)^{1 / K}
\end{aligned}
$$

Here, $v_{i}$ is the average wind speed during the time step i while $\mathrm{N}$ is the total wind speed data point other than zeros. The structure of wind captured by the Lidar system passing through the plane of wind turbine plane is illustrated through Figure 1. The wind turbulence model is illustrated in Figure 2. The turbulence model has various $\mathrm{y}-\mathrm{z}$ planes in the direction of the x-axis, such as planes 1, 2 and 3 . They are distributed over time and the speed information at the various point is obtained through time-domain variation in the rotor plane. The wind turbulence used $n$ bladed is a spatial model.

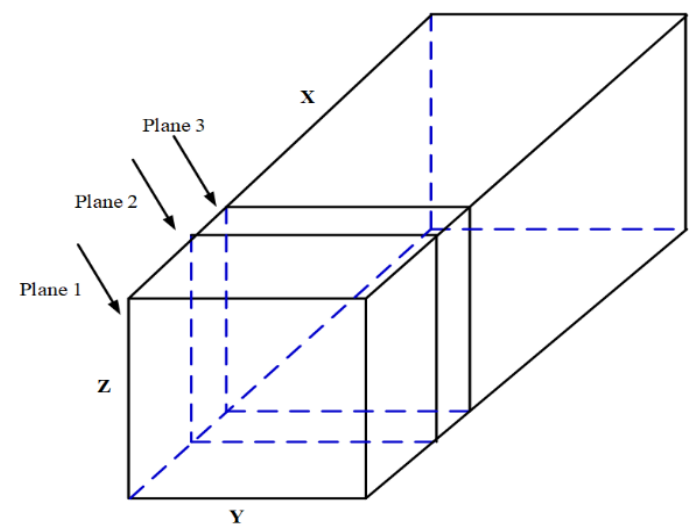

Figure 2. Wind turbulence model illustrated in bladed

\section{WIND TURBINE MODELLING}

The wind turbine system consists of various components illustrated in Figure 3. The output power acquired through wind speed is provided as (4):

$$
P_{a}=\frac{1}{2} \rho A C_{p}(\lambda, \beta) v
$$

$\rho$ indicates the air density while $C_{p}$ indicates the power of the coefficient. "A" indicates the rotor plane area, $\beta$ is pitch-angle while $\mathrm{v}$ is the wind speed.

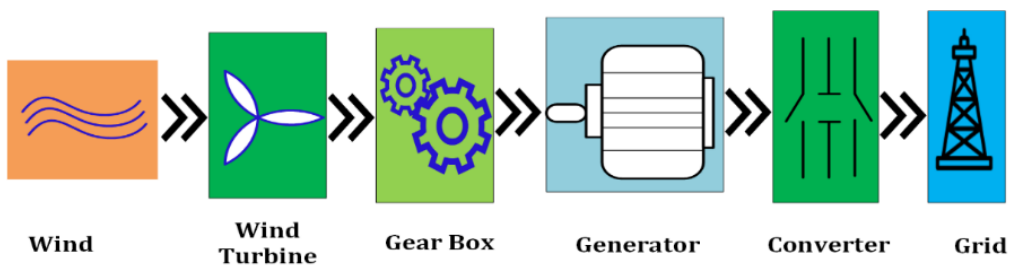

Figure 3. The parts of the wind turbine system

The coefficient of power is provided as (5) and (6),

$$
\begin{aligned}
& C_{p}=P / \frac{1}{2} \rho A V^{3} \\
& P=2 \rho A\left(V-V_{f t}\right)^{2} V_{f t}
\end{aligned}
$$


Here, the $V_{f t}$ is the fluctuating part of the wind speed relating to the x-axis component. The tip speed ratio $(\lambda)$ is formulated as $(7)$,

$\lambda=\omega_{r} R / V$

$\omega_{r}$ symbolizes the speed of the rotor while $\mathrm{R}$ indicates the radius of the rotor plane. The aerodynamic torque is represented as follows, $C_{q}$ denotes the coefficient of torque.

$$
\begin{aligned}
& T_{a}=1 / 2 \rho \pi R^{3} C_{q}(\lambda, \beta) V^{2} \\
& C_{q}=C_{p} / \lambda \\
& T_{f}=2 \rho A\left(V-V_{f t}\right) V_{f t} \\
& C_{T}=T_{f} / \frac{1}{2} \rho A V^{2}
\end{aligned}
$$

The $T_{f}$ is the thrust force and $C_{T}$ is the coefficient of the thrust. The active along with the reactive power of the generator used with the wind turbine is given as (12) and (13),

$$
\begin{aligned}
& P_{g}=\frac{3}{2}\left(V_{d} i_{d}+V_{q} i_{q}\right) \\
& Q_{g}=\frac{3}{2}\left(V_{q} i_{d}-V_{d} i_{q}\right)
\end{aligned}
$$

$V_{q}, V_{d}$ along with the $i_{d}, i_{q}$ denotes the voltage as well as current respectively in the d-q frame.

\section{DESIGN OF THE CONTROLLER}

\subsection{Conventional controller}

Normally, the PI/PID controller is used in wind turbines. These controllers are used for two purposes in wind turbine systems; the adjustment of the pitch angle and to regulate the torque. At the wind speed lower than the rated speed, the torque controller regulates in such a way to extract the maximum power out. The Pitch controller works with the increment of wind speed from the rated speed so that the output power remains within the rated limit. The conventional PI controller is illustrated in Figure 4. The values of $K_{p}, K_{i}$ and $K_{d}$ are used in these techniques, these values are calculated and optimized by various techniques to improve the efficacy of the designed controller.

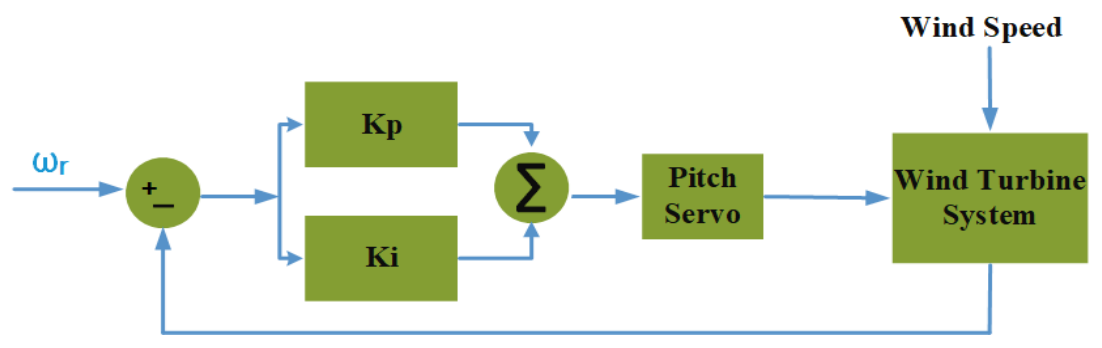

Figure 4. Block diagram of the conventional controller

\subsection{Modelled controller design}

The modelled controller is illustrated in Figure 5. Feedforward control system is implemented along with the Lidar system. The controller is linearized and the proposed controller block diagram concerning transfer functions is depicted through Figure 5. The $G_{w}$ denotes the wind evolution system, the $G_{1}$ and $G_{2}$ represents the transfer function of the linearized model wind turbine. $G_{L}$ is the transfer function of Lidar, $G_{F F}$ 
represents the transfer function of the feedforward controller whereas, $G_{F B}$ symbolizes the feedback controller.



Figure 5. The proposed controller along with the Lidar system

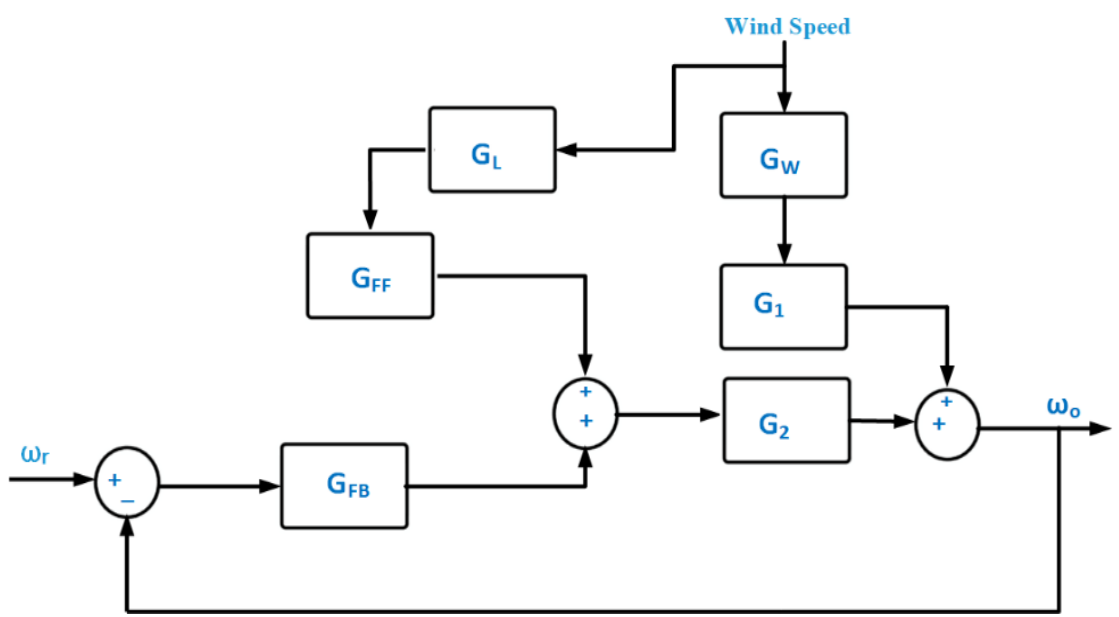

Figure 6. Block illustration of the proposed controller

The relation between output and input can be described as follows (14), (15) and (16);

$\omega_{o}=v G_{W} G_{1}+\left[V G_{L} G_{F F}+\left(\omega_{r}-\omega_{o}\right) G_{F B}\right] G_{2}$

$\left(1+G_{F B} G_{2}\right) \omega_{o}=\omega_{r} G_{F B} G_{2}-v\left(G_{W} G_{1}+G_{L} G_{F F} G_{2}\right)$

$\omega_{o}=\omega_{r} \frac{G_{F B} G_{2}}{1+G_{F B} G_{2}}+v \frac{G_{W} G_{1}+G_{L} G_{F F} G_{2}}{1+G_{F B} G_{2}}$

The objective of the control system for the controller is (17) and (18):

$$
\begin{aligned}
& \frac{G_{W} G_{1}+G_{L} G_{F F} G_{2}}{1+G_{F B} G_{2}}=0 \\
& G_{F F}=-\frac{G_{W} G_{1}}{G_{L} G_{2}}
\end{aligned}
$$




\section{SIMULATION AND RESULTS}

The simulation is performed in bladed software. The conventional controller along with the proposed controller is employed on the $2 \mathrm{MW}$ wind turbine. The parametric values of the wind turbine are given in the table 1.

Table 1. Wind turbine parameters.

\begin{tabular}{ll}
\hline Parameters & Values \\
\hline Rotor diameter & $80 \mathrm{~m}$ \\
Hub-height & $61.5 \mathrm{~m}$ \\
Blade length & $38.75 \mathrm{~m}$ \\
Rated Power & $2 \mathrm{MW}$ \\
Cut-in wind-speed & $4 \mathrm{~m} / \mathrm{s}$ \\
Cut-out wind-speed & $25 \mathrm{~m} / \mathrm{s}$ \\
Gearbox ratio & 83.33 \\
Density of the air & $1.225 \mathrm{Kg} / \mathrm{m}^{3}$ \\
\hline
\end{tabular}

The input wind is provided to the system which is illustrated in Figure 7. This input wind is given to the wind turbine system to attain the output values. The conventional along with the proposed technique which includes the lidar measurements as well as feedforward control is implemented on the $2 \mathrm{MW}$ wind turbine through GH Bladed simulation. Figure 8(a) illustrates the output power acquired from the wind turbine system by applying the input wind. Both techniques are compared, the conventional technique provides promising results but the proposed technique having wind evolution, Lidar measurement and feedforward control system shows better results by implanting the control ahead of the conventional control system.

Figure 8(b) represents the rotor speed ( $\mathrm{rad} / \mathrm{s})$ of the system by applying the conventional and the designed control strategy. The rotor speed gained from the modelled technique is lesser at the start as compared to the old control technique which reduces the loading effect. The output attained from the designed technique also indicates that the control system is working ahead of the conventional. Figure 8(c) denotes the pitch angle of the wind turbine blades which is applied to regulate the output power as per the wind speed crossing through the rotor plane. Variation in the pitch angle values is reflecting the behavior of output power along with the rotor speed.

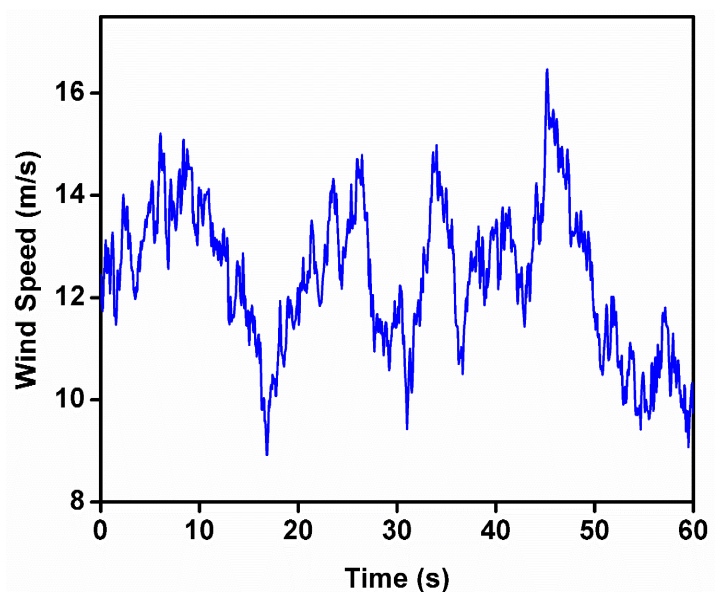

Figure 7. Input wind file fed to the wind turbine system.

Nacelle $\mathrm{x}$-acceleration values obtained from both techniques are illustrated in Figure 8(d). Loading along with the aging effect is dependent upon the value of acceleration. Nacelle acceleration achieved through the proposed technique is lesser than the conventional methodology which helps reduce the loading as well as aging effect. The results are much improved in the case of the proposed technique because of the ahead wind measurement which makes the control system more effective. Aerodynamic torque is presented in Figure 9. The aerodynamic torque achieved from the conventional as well as the proposed technique is shown. The effectual values attained from the proposed technique shows its efficacy. 


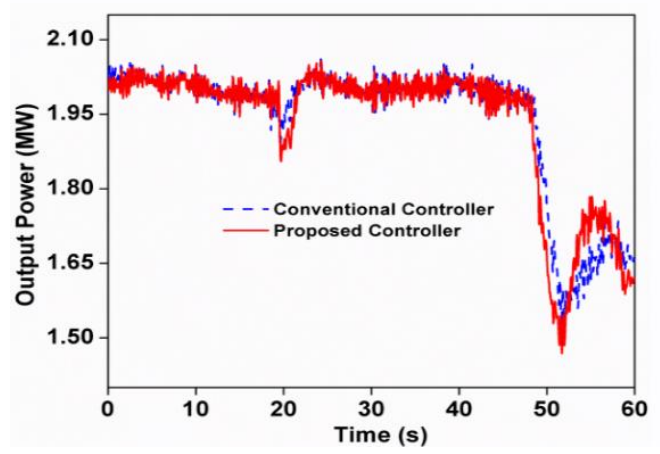

(a)

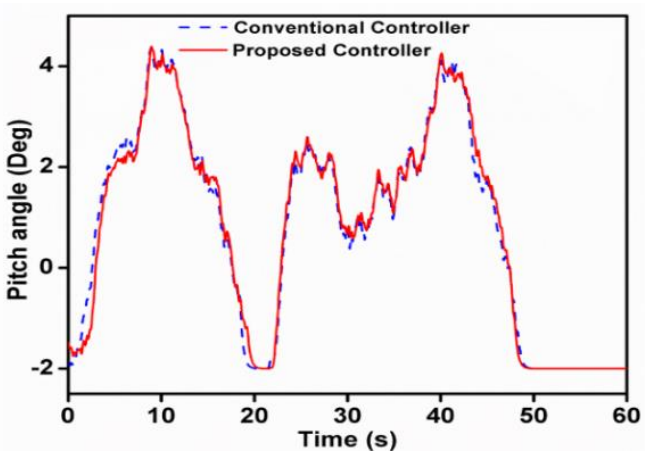

(c)

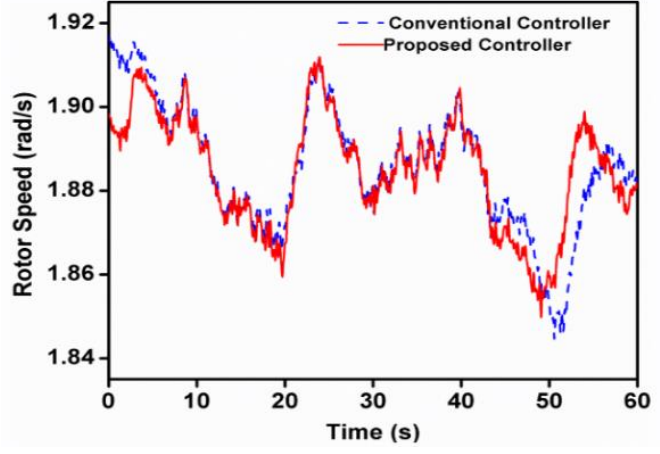

(b)

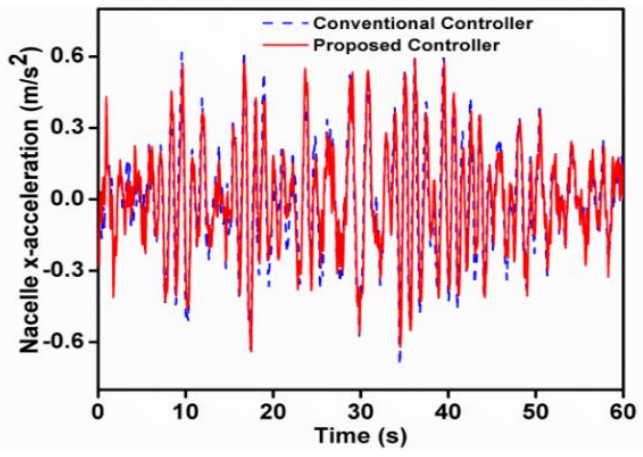

(d)

Figure 8. (a) Output power for the proposed and conventional controllers. (b) Rotor speed at the given input wind of the wind turbine system. (c) Pitch angle control of the system. (d) Nacelle $x$-acceleration of the wind turbine system.

These results conclude that the modelled control technique is $7.71 \%$ more effective and better than the previous reported techniques. Normally, the feedback control system is employed which acts after getting the response from the system. As the wind nature is uneven and undistributed that makes the control system more cumbersome and complex. Implementation of a feedback control system is not quite an effective approach in these conditions. Lidar measures the wind speed along with the direction before it passes through the rotor plane. This wind measurement data is very helpful for the controller to provide fruitful results. The feedforward control system along with the Lidar measurement data enhances the efficacy of the modelled control methodology.

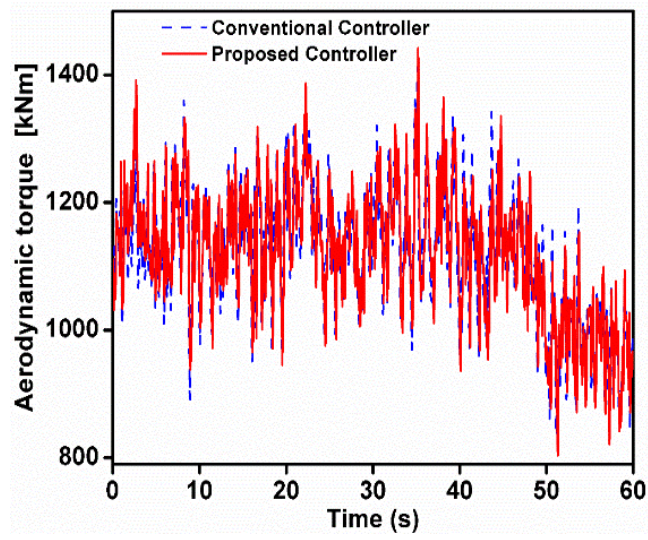

Figure 9. Aerodynamic torque of the system at provided techniques. 


\section{CONCLUSION}

This paper presents the Lidar technology to calculate the wind speed and then the measurements are fed to the controller to act accordingly. In conventional methodologies, mostly the feedback control techniques are employed and the wind is measured when it crosses the rotor plane through an anemometer. This makes the control system more complex and difficult because of the wind's turbulent nature. This paper proposes the Lidar based feed forward control system to measure the wind speed ahead and directs the control system to work as per the measurements. When wind passes through the rotor plane, the control system with the help of Lidar measurements already in a position to counter the uneven and undistributed nature of wind. The control technique is designed in bladed software and implemented on the 2 MW wind turbine through simulations. The proposed methodology is compared with the conventional one having a feedback control system. The involvement of a feed forward controller makes the control system more efficient and effective. The output results acquired from both techniques are illustrated and analyzed in the results section. The results obtained through the proposed techniques are much improved and better than the conventional. Rotor speed, pitch angle, output power and nacelle x-acceleration values prove the efficacy of the proposed Lidar based feed forward controller.

\section{REFERENCES}

[1] A. Saleem, A. Iqbal, et al., "The effect of environmental changes on the efficiency of the PV system," Indonesian Journal of Electrical Engineering and Computer Science (IJEECS), vol. 18, no. 1, pp. 558-564, 2020.

[2] J. W. Simatupang and K. Sulistiohadi, "Portable wind turbine for energy recharging device applications," J. Electr. Electron. Eng., vol. 1, no. 1, pp. 19-24, 2016.

[3] A. Iqbal, et al., "Proposed FLS-PID wind turbine pitch control for efficacious output," in 2019 International Symposium on Recent Advances in Electrical Engineering (RAEE), pp. 1-5, 2019.

[4] A. Iqbal, D. Ying, T. De, M. A. Hayat, A. Saleem, and R. Jamal, "Design and simulation for co-ordinated analysis of wind/solar with storage microgrid," Energy Reports, vol. 6, pp. 1504-1511, Dec. 2020.

[5] Meriem Otmane R., Mohammed L. S., Fayçel A., "MPPT control design for variable speed wind turbine," International Journal of Electrical and Computer Engineering (IJECE), vol. 5, no. 5, pp. 4604-4614, 2020.

[6] Yacine Hocini, Ahmed Allali, Houari Merabet Boulouiha, "Power fuzzy adaptive control for wind turbine," International Journal of Electrical and Computer Engineering (IJECE), vol. 10, no. 5, pp. 5262-5273, 2020.

[7] Quang-Vi Ngo, Chai Yi, Trong-Thang Nguyen, "The maximum power point tracking based-control system for small-scale wind turbine using fuzzy logic," International Journal of Electrical and Computer Engineering (IJECE), vol. 10 no. 4, pp. 3927-3935, 2020.

[8] A. Iqbal, D. Ying, A. Saleem, M. A. Hayat, M. Mateen, and M. S. Javed, "Effectual Proposed Pitch Controller of the Wind Turbine for Maximal Performance," in 2019 13th International Conference on Mathematics, Actuarial Science, Computer Science and Statistics (MACS), pp. 1-5, 2019.

[9] F. Yang, B. Han, Z. Xiang, and L. Zhou, "Individual pitch controller based on fuzzy logic control for wind turbine load mitigation," IET Renew. Power Gener., vol. 10, no. 5, pp. 687-693, May 2016.

[10] Aliyu Hamza Sule, Ahmad Safawi Mokhtar, Jasrul Jamani Bin Jamian, Attaullah Khidrani, Raja Masood Larik, "Optimal tuning of proportional integral controller for fixed-speed wind turbine using grey wolf optimizer," International Journal of Electrical and Computer Engineering (IJECE), vol.10, no.5, pp. 5251-5261, 2020.

[11] A. Iqbal, D. Ying, A. Saleem, M. A. Hayat, and M. A. Samad, "Modelling and comparison of different control techniques for 1-MW wind turbine to extract maximum power through pitch angle control," J. Comput. Theor. Nanosci., vol. 17, no. 2, pp. 1326-1331, Feb. 2020.

[12] Asl, Hamed Jabbari, and Jungwon Yoon, "Power capture optimization of variable-speed wind turbines using an output feedback controller," Renewable Energy, vol.86, pp. 517-525.

[13] A. Iqbal, D. Ying, A. Saleem, M. A. Hayat, and M. Mateen, "Proposed particle swarm optimization technique for the wind turbine control system," Meas. Control, vol. 53, no. 5-6, pp. 1022-1030, 2020.

[14] A. Iqbal, D. Ying, A. Saleem, M. Aftab, and K. Mehmood, "Efficacious pitch angle control of variable-speed wind turbine using fuzzy based predictive controller," Energy Reports, vol. 6, pp. 423-427, 2020.

[15] C. L. Bottasso, P. Pizzinelli, C. E. D. Riboldi, and L. Tasca, "LiDAR-enabled model predictive control of wind turbines with real-time capabilities," Renew. Energy, vol. 71, pp. 442-452, 2014.

[16] A. Clifton, et al., "IEA Wind Task 32: Wind Lidar Identifying and Mitigating Barriers to the Adoption of Wind Lidar," Remote Sens., vol. 10, no. 3, p. 406,2018.

[17] E. Simley, H. Fürst, F. Haizmann, and D. Schlipf, "Optimizing Lidars for Wind Turbine Control ApplicationsResults from the IEA Wind Task 32 Workshop,” Remote Sens., vol. 10, no. 6, p. 863, 2018.

[18] A. Scholbrock, P. Fleming, D. Schlipf, A. Wright, K. Johnson, and N. Wang, "Lidar-enhanced wind turbine control: Past, present, and future," in 2016 American Control Conference (ACC), pp. 1399-1406, 2016.

[19] R. Damiani, et al., "Assessment of wind turbine component loads under yaw-offset conditions," Wind Energ. Sci, vol. 3, no. 1, pp. 173-189, 2018.

[20] H. Dhiman, D. Deb, V. Muresan, and V. Balas, "Wake management in wind farms: An adaptive control approach," Energies, vol. 12, no. 7, p. 1247, 2019.

[21] M. Bromm, A. Rott, H. Beck, L. Vollmer, G. Steinfeld, and M. Kühn, "Field investigation on the influence of yaw misalignment on the propagation of wind turbine wakes," Wind Energy, vol. 21, no. 11, pp. 1011-1028, 2018. 
[22] P. McKay, R. Carriveau, and D. S.-K. Ting, "Wake impacts on downstream wind turbine performance and yaw alignment," Wind Energy, vol. 16, no. 2, pp. 221-234, Mar. 2013.

[23] D. Schlipf, D. Trabucchi, and O. Bischoff, "Testing of Frozen Turbulence Hypothesis for Wind Turbine Applications with a Scanning LIDAR System,"'in ISARS 2010, 2010.

[24] T. Mikkelsen, et al., "Lidar wind speed measurements from a rotating spinner," in European Wind Energy Conference and Exhibition, 2010.

[25] J. T. Richtsmeier, A. Zumwalt, E. J. Carlson, C. J. Epstein, and R. H. Reeves, "Craniofacial phenotypes in segmentally trisomic mouse models for Down syndrome,” Am. J. Med. Genet., vol. 107, no. 4, pp. 317-324, 2002.

[26] Gökhan Erdemir, Aydın Tarık Zengin, Tahir Cetin Akinci, "Short-term wind speed forecasting system using deep learning for wind turbine applications," International Journal of Electrical and Computer Engineering (IJECE), vol. 10, no. 6, pp. 5779-5784, 2020.

[27] J. V. Seguro and T. W. Lambert, "Modern estimation of the parameters of the Weibull wind speed distribution for wind energy analysis," J. Wind Eng. Ind. Aerodyn., vol. 85, no. 1, pp. 75-84, 2000. 